ORIGINAL ARTICLE

\title{
MAGNITUDE OF ASSOCIATED DISTRESS WITH BULIYING AND HARASSMENT AMONG MEDICAL TRAINEES
}

\begin{abstract}
\section{BACKGROUND AND AIMS}

Bullying is a persistent pattern of mistreatment that has been common worldwide with relatively high magnitude in schools and workplace. The adverse effects of bullying may lead to decreased social functioning, poor clinical performance and attendance ultimately low standardized results among medical trainees. Therefore this study aims to investigate the rate of bullying in medical trainees in order to analyze the adverse consequences affecting their health and well-being.
\end{abstract}

\section{METHODOLOGY}

The cross-sectional survey was conducted on medical trainees/house officers of MBBS and BDS who had completed at least 6 months of training in primary or tertiary care hospitals, recruited through the non-probability sampling technique. The data was collected through self-administered questionnaire.

\section{RESULTS}

A total of 70 participants filled the questionnaires including 8 males and 62 females. It was concluded that $70 \%$ participants faced bullying and $21.4 \%$ to $30 \%$ reported moderate to severe distress.

\section{CONCLUSION}

It was concluded that majority of medical trainees bullied during training while majority fails to report the issue. The act bullying or harassment was performed by senior staff and outsiders that lead to severe distress among students therefore crucial steps should be taken to address the situation for better physical and mental well-being.

\section{KEYWORDS}

Mental Well-Being, Physical Condition, Bullying, Trainee, Harassment.

\author{
Wajeeha Shakeel \\ Consultant Occupational Therapist \\ Medical AID Centre \\ wajeehashakeel@gmail.com
}

[Shakeel W. Magnitude of Associated distress with bullying and harassment among medical trainees-A cross sectional survey.Pak.j.rehabil.2020;9(2):30-35]

DOI:10.36283/pjr.zu.9.2/007 


\section{INTRODUCTION}

Bullying is a persistent pattern of mistreatment that has been common worldwide with relatively high magnitude in schools and workplace ${ }^{1}$ However, its exact prevalence is still unknown as the issue has not been addressed thoroughly ${ }^{2}$. According to Leisy and Ahmed ${ }^{3}$ the magnitude of people suffering without any gender bias highlights the sources of bullying behaviors and perceived barriers that stop victims to report bullying. Bullying is a relentless behavior that is menacing, undignified, odious, or malevolent at such extent that it undermines the self-confidence and sense of worth of the person ${ }^{4}$ It is further elaborated by Ellewood, characterized into five factors i.e. risk to specialized status, risk to one's own standing, segregation, work, and de-stabilization ${ }^{5}$. The estimate of occurrence of exploitation from bullying or harassment experienced is not only limited to illiterate population but also in workplace, particularly in healthcare system ${ }^{6}$. According to Ellwood ${ }^{7} 42 \%$ to $91 \%$ medical school trainees has been a victim of bullying that has led to adverse consequences of physical and mental well-being. The study conducted by Rodríguez et al ${ }^{8}$ revealed that common somatic complaints received from both bullies and victims are headaches, stomach pain, coupled with sleep deprivation, depression, and significant anxiety etc. These symptoms occurred as clusters that may cause an individual to have Bullying Syndrome 9 . However due to scarcity of evidence the level of bullying and harassment causing clusters of symptoms is still unknown. In addition, the adverse effects of bullying may lead to hazardous results includes decreased social functioning, poor clinical performance, attendance therefore ultimately low standardized results ${ }^{10}$. Despite, individuals who are both bullies and victims suffer the greatest risk for both mental health and behavioral problems, as opposed to individuals who are only bullies or victims ${ }^{11}$. The study conducted by Rosta and Aasland ${ }^{12}$ showed the statistics that around one in six students in USA suffer from bullying. The medical students reported that had suffered some form of harassment or discrimination throughout their course of study. A number of studies have also reported that variable forms of abuse; including verbal, physical, sexual, academic harassment and racial bias is a great problem for trainees that are often neglected ${ }^{13}$. Such atmospheres during training create hostile work environments and induce distress and uneasiness that may impair and low performance ${ }^{14}$. It was also evident that trainee who were frequently harassed failed to complete assignments or provide optimal patient care ${ }^{15}$. While it tends to be hard to identify with the domineering bully, it's basic that guardians and school authorities perceive that harassers take part in tormenting conduct which is as it should be. Without assistance, the conduct will proceed, and conceivably intensify, after some time. One the contrary, trainees who were harassed had more emotional health problems, family life, social responsibility and disruptions compared with no harassed trainees from decades ${ }^{16}$. Moreover, studies reported that harassed trainees were more prone to depression, anxiety, insomnia, and appetite loss and some of them even drink alcohol for escape than no harassed trainees ${ }^{17}$. Despite of the facts, the magnitude of bullying and harassment in low-middle income countries are yet to be known therefore this study aims to investigate the rate of bullying in medical trainees in order to analyze the adverse consequences affecting their health and well-being. All children are unique and are probably going to show differing practices during or in the wake of tormenting by a companion. With social hostility on the ascent and cyber bullying simpler than at any other time, it should be noticed that tormenting can be continuous for significant stretches of time before understudies look for help. A study conducted by Rosta and Aasland 18 concluded that occurrence of workplace bullying in Pakistan healthcare system among junior doctors or interns different sources of bullying behaviors that have led to cultural or social barriers which stop victims from reporting the issue. According to a survey, the most common predator of bullying was an educated and cultured part of society that is consultants who mostly bully their juniors ${ }^{19}$. However, the issue is never been reported to authorities due to fear of people's perspective. This social dilemma causes high prevalence of most victims to remain silent. Due to increased bullying in health institutions and hospitals, the staff has been suffering from increased stress, anxiety, depression, low attendance ratio and intention to leave the training at the peak of career including undergradvate or postgraduate trainees ${ }^{20}$. The study conducted by Rouse et al ${ }^{21}$ showed that bullying and harassment is an antisocial behavior that has no relation with any of the socio-demographic variables however prevalence is unreported. A survey conducted by Leisy and Ahmad ${ }^{22}$ reported that specialty board residents of middle-east countries are mistreated during internship during first year that effect their mental health. In spite of very strict laws in these countries response rate was $84 \%$ i.e. $96.6 \%$ believes that mistreatment exists. Although intended population was a very small ratio but response rate was indeed alarming. In addition, a meta-analysis stated that issues of bullying and harassment exist around the globe ${ }^{23}$. However, due to lack of law and order in this regard in most of the countries this behavior is persistent for years ${ }^{24}$. Therefore, society laws should be enforced in medical institutions to ensure such non-professional attitude to be addressed in some extent. In this modern era, bullying has become a community problem in the healthcare system that has noteworthy implication for medical trainees that are inevitable. For a period of time bullying was only the 
concern of teachers, educationalists, and psychologists as it was considered to happen at that level only but according to current definitions, abuse, victimization and aggression are highlighted addressing a big social problem ${ }^{24}$. Over the decade people are more aware of the adverse effects of bullying, but it still a range of provoking and bullying behaviors exists. The most common route of bullying reported by the victims is name calling, followed by cheesy comments and rumor spreading which doesn't even exists ${ }^{25}$. The social, behavioral, and emotional correlates of bullying and victimization in a school-based sample ${ }^{26}$.

In the last few years, there has been an increasing amount of research showing the concurrent and long-term consequences of bullying and being bullied by peers. Although in the past few years an increasing amount of researches are conducted on bullying and harassment in medical trainees but unfortunately impediments to the training process remain a major concern as it remain highly prevalent in training due to which a negative behavior is detrimental to almost most of the trainees. Bullying and harassment are the behaviors that make feel someone imitated or offended. Several studies stated that the factor is common in hospitals, especially among medical trainees/house officers that may lead to certain level of distress. However, its magnitude has not been analyzed. Therefore, the aim of study is to evaluate factors associated with distress and its level as a result of bullying or harassment in order to address psychological issues.

\section{METHODOLOGY}

\section{Study Setting}

Data was collected from primary and tertiary care hospitals of Karachi including Dr. Ziauddin Hospital North and Clifton, Dow University of Health Sciences (DUHS), Liaquat National Hospital (LNH) and Jinnah Postgraduate Medical Centre (JPMC).

\section{Target Population}

Medical trainees or house officers of MBBS and BDS

\section{Study Design}

Cross-sectional study.

\section{Duration of Study}

6 months.

\section{Sampling Technique}

Non-Probability Convenient Sampling Technique.

\section{Sample Size}

The sample was calculated using online software Open EPI (External Presentation Interface), open source calculator version 3.01. Considering 100,000 population size with $50 \%$ of anticipated frequency, therefore sample of 700 was calculated at $95 \%$
Confidence Interval and $5 \%$ margin of error.

\section{Sample Selection Inclusion criteria}

Both male and female medical trainees'/house officers of MBBS and BDS who has completed at least 6 months of training in primary or tertiary care hospitals will be included.

\section{Exclusion criteria}

Trainees of allied health sciences or those who refused to participate.

\section{Data Collection Procedure}

Data was collected from primary and tertiary care hospitals of Pakistan through Google Docs forms. The medical trainees/house officers were recruited through convenience sampling technique as per the inclusion criteria. Prior to data collection, participants were provided with informed consent in order to have detailed information about the study. Followed by the consent, participants were given self-administered questionnaire in order to analyze the magnitude of distress.

\section{Data Collection Tool}

Data was collected through a self-administered questionnaire which is comprised of demographic details of the participant along with open and close questions regarding perspective of an individual towards bullying and harassment, related causes, factors, associated person, involvement of workplace and safety measures to bullying.

\section{Data Analysis Strategy}

The collected data was entered and analyzed on Microsoft excel 2013 version. The Demographic details of participants were represented through descriptive statistics; on the other hand participant's responses are represented through frequency and percentage.

\section{Ethical Considerations}

All participants were given informed consents in order to provide detail information regarding the study. Before commencement of the study, consent was taken to proceed further. The information of all the participants was kept confidential under investigator whereas participants were allowed to refuse anytime to take part in the study or provide any information related to study.

\section{Public Health Significance}

The study will be significant to identify the magnitude of bullying and harassment in healthcare sectors. This study will also promote the need for addressing this issue in hospitals to prevent medical trainees from these factors. Furthermore, the need for addressing the psychological problems among medical trainees will also be raised. 


\section{RESULTS}

A total number of 70 participants filled the questionnaires which includes 8 males and 62 females of age range $24-30$ years.

In the results it is observed that the majority of participants i.e. $70 \%$ respond to being bullied during the course of their training while only $30 \%$ disagreed to the question. Moreover, around eighty percent $(80 \%)$ of the participants reported bullying in the past months followed by $14.3 \%$ and $5.7 \%$ respectively represented in Figure- 1 .

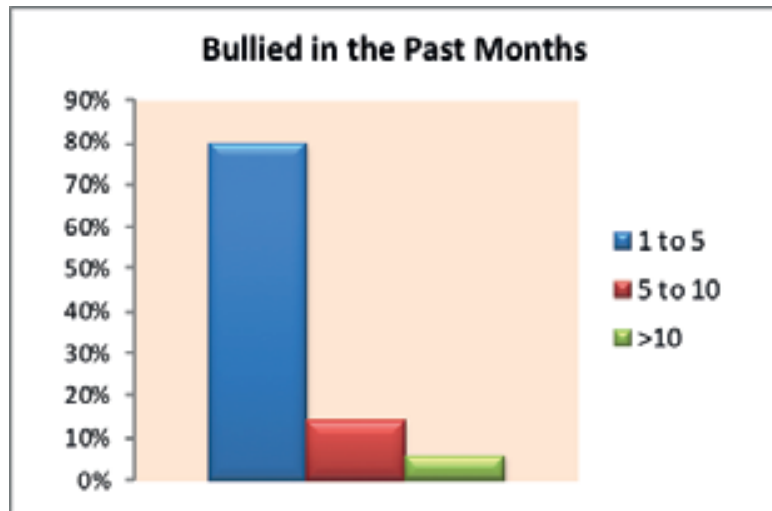

Figure.1 Participants response to bullying in past months

It was reported that $24.3 \%$ participants were bullied in gatherings at a workplace, $17.1 \%$ at night duties in hospital while $20 \%$ were bullied during training and at social media sites, however only $7.1 \%$ participants bullied while waiting for a patient in hospital as shown in Figure-2. It was also shown that around $32.9 \%$ participants had never tell anyone being bullied while almost $18.6 \%$ and $11.4 \%$ talked about the issue with their parents and friends besides that only $4.3 \%$ participants inform about bullying to their supervisor or counselor respectively as represented below.

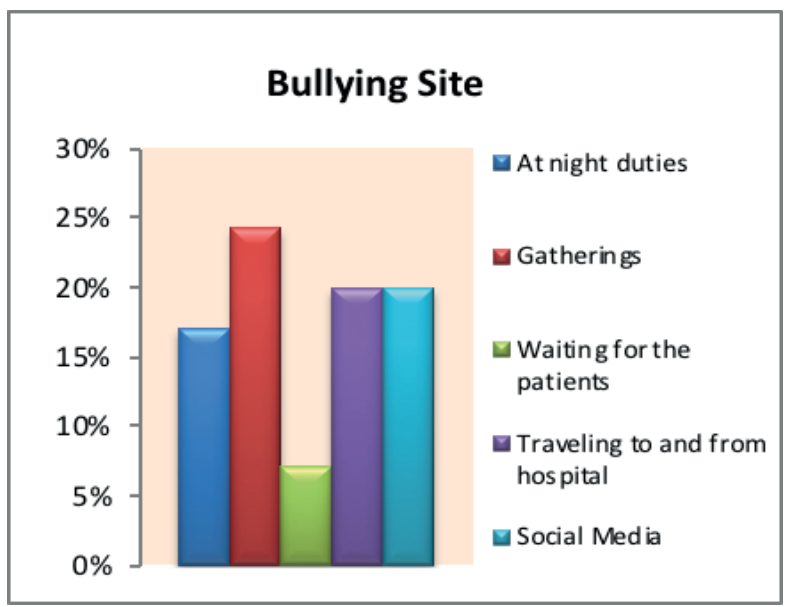

Figure.2 Participants response to bullying sites question
The findings of the study further revealed that $40 \%$ of the participants were bullied from an outsider at the workplace while $32.9 \%$ of the participants bullied from the senior staff. Moreover, as it is shown in figure, around $14.3 \%$ and $12.9 \%$ were bullied and harassed by their batch mates or senior residents as Figure-4. In the observed results, it was also concluded that around $30 \%$ of participants were reported to be in severe distress after bullying whereas $21.4 \%$ and $20 \%$ were found to be in moderate and mild distress respectively as shown in Figure-3.

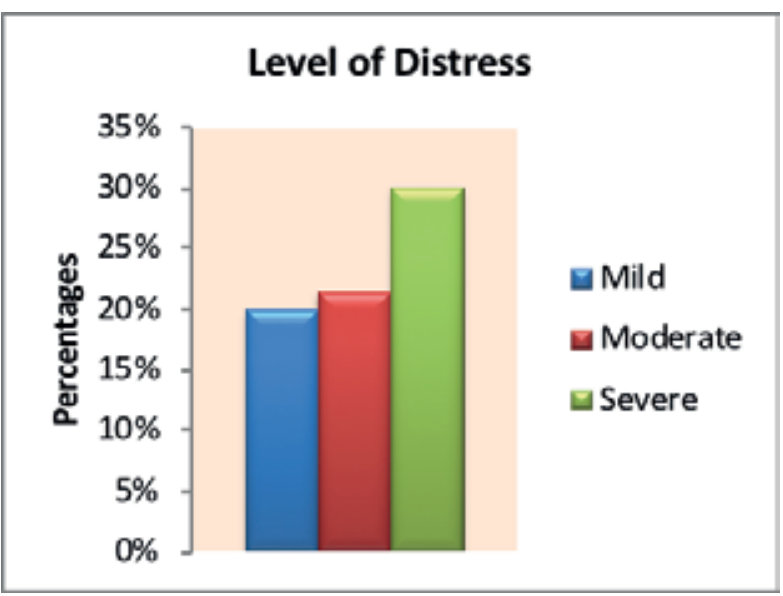

Figure.3 Participants response to level of distress due to bullying question

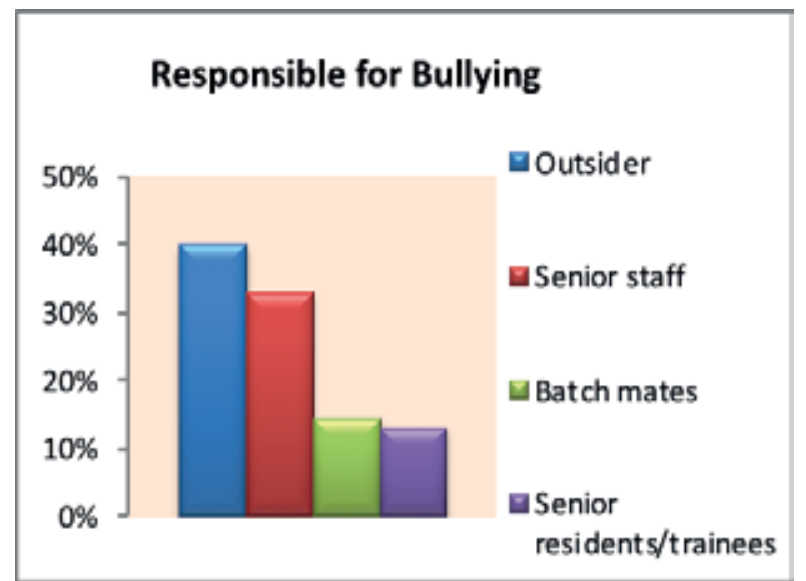

Figure-4 Participants response to people responsible for bullying question

Moreover, it was showed that $60 \%$ participants had respond to the terrible management of a workplace in addressing bullying while $35.7 \%$ and $4.3 \%$ participants respond to the effective role of workplace.

\section{DISCUSSION}

The findings of our results revealed that majority of medical trainees suffer from bullying during their training are failed to share the incident and suffering from varying level of distress that may lead 
towards the adverse physical and mental consequences. Similarly, a cross-sectional study conducted in Quetta also showed that 35\% participants had experience of bullying that affects their peer and institutional relationship while it was also revealed that number of students have an adequate knowledge of bullying while $65 \%$ has never subjected to it '. Further studies also highlighted that male students are more bullied rather than female ${ }^{2}$. However in our study, males participants were in small proportionate so estimation of bullying cannot be subjected to gender bias. Therefore, number of studies must be conducted to investigate the issue in counterpart gender ${ }^{3}$. Several surveys revealed that medical residents has been linked to higher rate of burnout as they were reported to be suffering from depression ${ }^{7}$ discovering solutions for medical resident bullying. It was revealed that individuals may face emotional exhaustion and depersonalization that may leads to detachment from the job and feeling of inefficacy ${ }^{20}$. Likewise in our study, majority of the participants reported to leave the workplace after bullying while number of individuals seeks revenge after it. Therefore, it has been evident that bullying behavior may lead towards the aggression and thoughts of desertion at the workplace ${ }^{13}$ Pilot study on the prevalence of abuse and mistreatment during clinical internship: a cross-sectional study among first year residents in Oman.

Several studies also concluded that bullying leads the individual of rethink of their career selection after the mistreatment ${ }^{15}$. In particular they often quit their training and search for another options due to decreased satisfaction and lack of personal achievement ${ }^{27}$. Similarly, it was showed that $20 \%$ residents didn't wish to pursue medicine and would even advise others not to choose this field ${ }^{18}$ whereas, due to certain limitation our study didn't investigated alternate job choices of bullying. Studies conducted in abroad reported that majority of students were cyber bullied because of the social media sites where as in our study only $20 \%$ participants reported bullying at social application although, the issue is now-a-days common due to increased use of modern technology ${ }^{19}$. Further, it was observed that bullied students felt depressed after the occurrence incidence that is found to equivalent in both victim and bullies.

In modern era, bullying has become a crucial subject that has affect many but only reported by some. This is due to lack of awareness, fear of rejection or failure to achievement in one's career. Due to certain limitations in our questionnaire, some questions was not incorporated and relatively a small sample size causes limitation to analyze factors of bullying behavior and its magnitude in targeted population. Therefore, considering a larger sample, a large scale surveys should be conducted to analyze the burden of bullying, also this leads to aware the need of counselors or psychiatrist to address this issue as majority individuals fails to talk about it that may lead to serious health concerns.

\section{CONCLUSION}

The findings of our study revealed that $70 \%$ of medical trainees bullied during training while majority fails to report the issue. In particular, the act bullying or harassment was performed by senior staff and outsiders that lead to severe distress among students therefore crucial steps should be taken to address the situation for better physical and mental well-being.

\section{REFERENCE}

[1] Arseneault L. The long-term impact of bullying victimization on mental health. World psychiatry. $2017 ; 16(1): 27$.

[2] McAuley J. Addressing Bullying: Learning from Experience 2019.

[3] Ahmer S, Yousafzai AW, Bhutto A. Bullying of medical students in Pakistan: a cross-sectional questionnaire survey. PLoS one. 2008;3(12).

[4] Anagnostopoulos F, Demerouti E, Sykioti P, Niakas D, Zis P. Factors associated with mental health status of medical residents: a model-guided study. J. Clin. Psychol.. 2015;22(1):90-109.

[5] Al-Shafaee M, Al-Kaabi Y, Al-Farsi Y, White G, Al-Maniri A, Al-Sinawi $\mathrm{H}, \mathrm{Al}-\mathrm{Adawi}$ S. Pilot study on the prevalence of abuse and mistreatment during clinical internship: a cross-sectional study among first year residents in Oman. BMJ open. 2013;3(2):e002076.

[6] Bonafons C, Jehel L, Coroller-Béquet A. Specificity of the links between workplace harassment and PTSD: primary results using court decisions, a pilot study in France. International archives of occupational and environmental health. 2009;82(5):663-8.

[7] Chambers CN, Frampton CM, McKee M, Barclay $M$. 'It feels like being trapped in an abusive relationship': bullying prevalence and consequences in the New Zealand senior medical workforce: a cross-sectional study. BMJ open. 2018;8(3):e020158.

[8] Crutcher RA, Szafran O, Woloschuk W, Chatur F, Hansen C. Family medicine graduates' perceptions of intimidation, harassment, and discrimination during residency training. BMC medical education. $2011 ; 11(1): 88$.

[9] Cohen JS, Patten S. Well-being in residency training: a survey examining resident physician satisfaction both within and outside of residency training and mental health in Alberta. BMC medical education. $2005 ; 5(1): 21$.

[10] Englander EK. Understanding bullying behavior: What educators should know and can do. 
American Educator. 2017;40(4):24.

[11] Ellwood A. Safety and Respectful Treatment of Medical Students and Residents. Academic Psychiatry. 2010;34(1):79-80.

[12] Frank E, Carrera JS, Stratton T, Bickel J, Nora LM. Experiences of belittlement and harassment and their correlates among medical students in the United States: longitudinal survey. bmj. $2006 ; 333(7570): 682$.

[13] Fnais N, al-Nasser M, Zamakhshary M, Abuznadah W, Al-Dhukair S, Saadeh M, Al-Qarni A, Bokhari B, Alshaeri T, Aboalsamh N, BinAhmed A. Prevalence of harassment and discrimination among residents in three training hospitals in Saudi Arabia. Annals of Saudi medicine. 2013;33(2):134-9.

[14] Haq NU, Arshad Z, Lehri SA, Nasim A, Saood M, Zarak MS. Assessment of Knowledge, Perception and Prevalence of Bullying Practices among Medical Students of Quetta. J Adv Med Med Res. 2018:1-20.

[15] Gullander $M$, Grynderup $M$, Hansen ÅM, Hogh A, Persson R, Kolstad HA, Mors O, Kaerlev L, Bonde JP. Are changes in workplace bullying status related to changes in salivary cortisol? A longitudinal study among Danish employees. J. Psychosomat. Res., 2015;79(5):435-42.

[16] Farley S, Coyne I, Sprigg C, Axtell C, Subramanian $G$. Exploring the impact of workplace cyber bullying on trainee doctors. Medical education. 2015;49(4):436-43.

[17] Fraser K, Clarke G, Hager B, Katzman J, Washinsky $M$, Brown C. Residents and faculty work together to reduce faculty intimidation of residents and improve morale. Academic Psychiatry. 2014;38(2):217-20.

[18] Golmaryami FN, Frick PJ, Hemphill SA, Kahn RE, Crapanzano AM, Terranova AM. The social, behavioral, and emotional correlates of bullying and victimization in a school-based sample. J. Abnorm. Child Psychol2016;44(2):381-91.

[19] Harvey M, Treadway D, Heames JT, Duke A. Bullying in the 21 st century global organization: An ethical perspective. J. Bus. Ethics. 2009;85(1):27.

[20] Imran N, Jawaid M, Haider II, Masood Z. Bullying of junior doctors in Pakistan: a cross-sectional survey. Singapore Med J. 2010;51 (7):592-.

[21] Iossi Silva MA, Pereira B, Mendonça D, Nunes B, Oliveira WA. The involvement of girls and boys with bullying: an analysis of gender differences Int. J. Environ. Res 2013;10(12):6820-31. Islamoska S, Grynderup MB, Nabe-Nielsen K,

[22] Høgh A, Hansen AM. Does the Association between Workplace Bullying and Post-Traumatic Stress Symptoms differ across Educational Groups?. J. Eur. Psychol. Stud. 2018 17:9(1). Krämer N, Sobieraj S, Feng D, Trubina E,

[23] Marsella S. Being bullied in virtual environments: experiences and reactions of male and female students to a male or female oppressor. Frontiers in psychology. $2018 ; 9: 253$.

Karim S, Duchcherer M. Intimidation and

[24] harassment in residency: a review of the literature and results of the 2012 Canadian Association of Interns and Residents National Survey. Can. Med. Educ. J. 2014;5(1):e50. 